\title{
LEPTOSPIROSIS IN KOLKATA- A RETROSPECTIVE STUDY OVER EIGHT YEARS IN A MEDICAL COLLEGE AND HOSPITAL
}

\author{
Saha Dalal Bibhas' ${ }^{1}$ Roy Swagnik2, Dasgupta Rajat³, Saha Dalal Barun ${ }^{4}$ \\ ${ }^{1}$ Assistant Professor, Department of Pathology, PGIMSR, Joka \\ ${ }^{2}$ Assistant Professor, Department of Microbiology, KPCMCH. \\ ${ }^{3}$ Tutor, Department of Microbiology, KPCMCH. \\ ${ }^{4}$ Professor, Department of Microbiology, KPCMCH.
}

\section{ABSTRACT}

\section{BACKGROUND}

Leptospirosis is a bacterial infectious disease that affects humans and animals. It is caused by pathogenic spirochetes of the genus Leptospira. It is a specific zoonotic disease with worldwide distribution with a much greater incidence in tropical countries like India. In West Bengal, especially in Kolkata, there is high average rainfall with water holding capacity of soil. Also, there is a huge natural population of rodents and stray dogs which serve as the carrier of the disease. The sanitary arrangements for the roadside slaughtering houses are very poor. In the rainy season, parts of the city remain waterlogged.

The above points are the sole reasons for the cases of leptospirosis in the city of Kolkata. There were considerable good number of cases from the surrounding areas.

\section{MATERIALS AND METHODS}

The study was conducted between 2009 to 2017 in a Medical College and Hospital, Kolkata. Samples were collected from clinically suspected cases, with history of possible exposure, in the rainy seasons and included the same in our study for testing. We got a total of 42 suspected cases during the eight-year study period. Cases were mostly from Kolkata, suburbs, North and South 24 Parganas and Midnapore. Microscopic agglutination test (MAT) following standard procedures was used. 7 Reference strains belonging to 12 serogroups were included in the MAT panel as antigens.

\section{RESULTS}

Of the 42 sera tested, 34 (30.4\%) were positive for IgM antibodies against Leptospira, and 32 of these were positive by latex agglutination method. Also, MAT was positive in thirty of these thirty-four positive patients. Antibodies were found against several serogroups (Australis 1:100; Bataviae 1:200; Canicola 1:200; Copenhageni 1:400; Sejroe 1:800; Ballum 1:100; Icterohaemorrhagiae 1:100; Pyrogenes 1:800). But antibodies of multiple serogroups were not found in a single specimen.

\section{CONCLUSION}

Current methods for the direct detection of Leptospires are either slow or of limited reliability so that serology is often the most appropriate diagnostic method. Treatment with effective antibiotics should be initiated as soon as the diagnosis of leptospirosis is suspected and preferably before the fifth day after the onset of illness. The benefit of antibiotics after the fifth day of the disease is controversial. However, most clinicians treat with antibiotics regardless of the date of onset of the illness. These were done in all of these cases and there was no death among the four positive cases.

\section{KEYWORDS}

Leptospire, SAPH, SPHL, Leptospirosis, Spirochetes, SPF.

HOW TO CITE THIS ARTICLE: Bibhas SD, Swagnik R, Rajat D, et al. Leptospirosis in Kolkata- A retrospective study over eight years in a medical college and hospital. J. Evolution Med. Dent. Sci. 2017;6(87):6066-6068, DOI: 10.14260/jemds/2017/1317

\section{BACKGROUND \\ Leptospirosis is a bacterial infectious disease that affects humans and animals. It is caused by pathogenic spirochetes of the genus Leptospira. It is a specific zoonotic disease with worldwide distribution with a much greater incidence in tropical countries like India. It is a very common zoonosis in the world associated with rodents in poor sanitation areas in rainy season commonly in the working groups like farmers,}

'Financial or Other Competing Interest': None.

Submission 12-06-2017, Peer Review 18-10-2017,

Acceptance 25-10-2017, Published 30-10-2017.

Corresponding Author:

Dr. Roy Swagnik,

\#26, Nutan Pally, Khardaha,

P. O. Titagarh,

Kolkata-700119.

E-mail: swagnik.roy1442@gmail.com

DOI: $10.14260 / \mathrm{jemds} / 2017 / 1317$ gardeners, cattle handlers, mostly those who are exposed to mud, soil or animal urine contaminated water. ${ }^{1}$ In West Bengal, especially in Kolkata, there is high average rainfall with water holding capacity of soil. Also, there is a huge natural population of rodents and stray dogs which serve as the carrier of the disease. The sanitary arrangements for the roadside slaughtering houses are very poor. In the rainy season, parts of the city remain waterlogged. The above points are the sole reasons for the cases of leptospirosis in the city of Kolkata. ${ }^{2}$ In China and Korea, severe pulmonary haemorrhage, as a fatal and severe complication of leptospirosis and potent cause of death due to leptospirosis was identified. ${ }^{3}$

The presence of Leptospiral antigen in the lung can easily prove the pivotal role of the microorganism in the generation of the tissue lesions. ${ }^{4} \mathrm{SAPH}$, also termed as severe pulmonary haemorrhagic leptospirosis (SPHL), severe pulmonary form of leptospirosis (SPFL) or Leptospiral pulmonary 
haemorrhage Syndrome (LPHS), is considered by some authors as a form of leptospirosis distinct from Weil's disease because pulmonary manifestations are found to occur solely without any kind of hepatic or renal manifestations. ${ }^{5}$ The mortality rate of leptospirosis is high, reaching $2.5 \%$ to $16.45 \%$. At the age of over 50 years mortality rate can be up to $56 \%$. When leptospirosis patient is accompanied by a yellow lining of the eye indicating damage to the liver tissues, the risk of mortality will be higher. Several publications reported mortality rates between $3 \%-54 \%$ depending on the infected organ system. ${ }^{6}$ Initially in China and Korea, it was thought that only one particular serotype is showing pulmonary manifestation but later several genospecies and serovars of Leptospira have been shown to cause pulmonary haemorrhage. ${ }^{7}$ The haemorrhagic manifestations are the main clinical identification features in thrombocytopenic cases. Some authors described that thrombocytopenia as significant predictor for renal failure in leptospirosis patients. Neurological signs and symptoms are seen in some patients, their clinical feature being stiff neck with altered sensorium. ${ }^{8}$, In the Indian case scenario, total case fatality ratio in Chowdry's case series was 13.2 percent. ${ }^{10}$ There were considerable good number of cases from the surrounding areas. So a study was planned from November 2009 to September 2017 to inspect the real case scenario of leptospirosis in the surrounding areas. The weather conditions, waterlogging and presence of roadside meat shops considerably create an ideal environment for the spread of the disease. There were also few clinicians who inspected and suggested for evaluation of some patients for leptospirosis which was another contributing factor for planning this study.

\section{MATERIALS AND METHODS}

The study was conducted between 2009 to 2017 in a Medical College and Hospital, Kolkata. Samples were collected from clinically suspected cases, with history of possible exposure, in the rainy seasons and included the same in our study for testing. We got a total of 42 suspected cases during the eightyear study period. Cases were mostly from Kolkata, suburbs, North and South 24 Parganas and Midnapore. It is a retrospective study based on secondary data from records.

\section{Laboratory Procedure}

Serum was separated from blood samples and stored at $20^{\circ} \mathrm{C}$ until it was processed. Sera samples were tested for the presence of anti-Leptospiral antibodies using Microscopic agglutination test (MAT) following standard procedures. 7 reference strains belonging to 12 serogroups were included in MAT panel as antigens. These include Australis (serovar Australis, strain Ballico), Autumnalis (serovar Autumnalis, strain Rachmat), Bataviae (serovar Bataviae, strain Swart), Canicola (Serovar Canicola, strain Hond Utrecht IV), Grippotyphosa (serovar Grippotyphosa, strain Moskva V), Icterohaemorrhagiae (Serovar Icterohaemorrhagiae, strain RGA), Javanica (Serovar Poi, strain Poi), Pomona (serovar Pomona, strain Pomona), Sejroe (serovar Hardjo, strain Hardjoprajitno), Ballum (serovar Ballum, strain Mus 127), Cynopteri (Serovar Cynopteri, strain 3522C) and Pyrogenes (Serovar Pyrogenes, strain Salinem). The antigens used were 5-7 days' old autoagglutination-free cultures grown in Ellinghausen-McCullough-Johnson-Harris (EMJH) medium
(Difco, Sparks, MD) with approximately $1 \times 10^{8}$ to $2 \times 10^{8}$ organisms/mL. MAT was done at doubling dilutions starting from 1 in 25. Positive samples were titrated up to end titres. A titre of 1 in 50 or more against any of the serovars was considered as evidence of Leptospiral infection.

\section{RESULTS}

Of the 112 sera tested, 34 (30.4\%) were positive for IgM antibodies against Leptospira, and 32 of these were positive by latex agglutination method. Also, MAT was positive in thirty of these thirty four positive patients. In this patient, antibodies were found against several serogroups (Australis 1:100; Bataviae 1:200; Canicola 1:200; Copenhageni 1:400; Sejroe 1:800; Ballum 1:100; Icterohaemorrhagiae 1:100; Pyrogenes 1:800). But antibodies of multiple serogroups was not found in a single specimen. In one participant without clinical symptoms, seropositivity for serogroups Icterohaemorrhagiae/Copenhageni 1:100 were found. Clinical disease was mild in most cases with fever most frequently reported (100\%) followed by headache $(23 / 34)$ and muscle pain (34/34). Diarrhoea and renal impairment were reported from single patients, respectively. Jaundice, pulmonary haemorrhage, meningoencephalitis, or other severe manifestations of leptospirosis were not reported. No deaths were reported. Thirty three of the thirty-four patients required hospitalisation.

\begin{tabular}{|c|c|c|c|}
\hline & $\begin{array}{c}\text { Prevalence } \\
\text { Range } \\
\left(\min , \text { max }^{*} \text { ) }\right.\end{array}$ & $\begin{array}{l}\text { Sample } \\
\text { Size (n) }\end{array}$ & $\begin{array}{c}\text { Diagnostic } \\
\text { Test }\end{array}$ \\
\hline \multirow[t]{2}{*}{ Baruipur } & $50 \%[12]$ & 24 & MAT, $\geq 1: 50$ \\
\hline & & & ELISA \\
\hline Sundarban & $28 \%[04]$ & 14 & MAT, 1:50 \\
\hline Canning & $33 \%[03]$ & 09 & $\begin{array}{l}\text { ELISA MAT, } \\
\text { ELISA0 }\end{array}$ \\
\hline $\begin{array}{l}\text { Waterlogged } \\
\text { Suburbs }\end{array}$ & $11.7[02]$ & 17 & MAT, ELISA \\
\hline \begin{tabular}{|l|} 
Lakhmikantapur \\
\end{tabular} & $23[03]$ & 13 & MAT, ELISA \\
\hline Diamond Harbour & $28.5[02]$ & 07 & $\begin{array}{l}\text { MAT }>1: 50, \\
\text { ELISA }\end{array}$ \\
\hline Medinipur & $28.6[08]$ & 28 & MAT, ELISA \\
\hline \multicolumn{4}{|c|}{$\begin{array}{l}\text { Table 1. Leptospirosis Prevalence by Geographic Region } \\
\text { Geographic Region with Prevalence Data }\end{array}$} \\
\hline
\end{tabular}

\section{DISCUSSION}

Leptospirosis occurs in the form of seasonal post-monsoon outbreaks with considerable mortality. Leptospires have good affinity to areas where heavy rainfall results in waterlogging of the land. Human populations residing in such environment are at higher risk of acquiring Leptospiral infection. The majority of the affected population belongs to the agriculture community. The present study has been undertaken as a retrospective study. There was $30.4 \%$ positivity observed among suspected cases. Several different authors have described outbreak of Leptospira in different parts of our country as well as the world. Sethi et al from North India reported $11.7 \%$ occurrence (2004-2008) in 2004 and $20.5 \%$ in 2008. A total of 215 number of cases has been reported from South India from the city of Coimbatore, TamilNadu (2007 - 2009). 130 cases have been reported from Trivandrum, Kerala in 2005. A huge number of cases are getting reported from Andaman Islands, where this is an 
endemic disease. In our positive cases also, one patient has given the history of travelling to Andaman. Mostly waterlogged conditions of Kolkata and Road side butcher houses can also be attributed to the Seropositive cases.

So the above results clearly justify that the study was planned at right time and the results also signify the same.

\section{CONCLUSION}

Current methods for the direct detection of leptospires are either slow or of limited reliability so that serology is often the most appropriate diagnostic method. Moreover, in practice, patients often seek medical care or are admitted in hospitals when they have already been ill for a sufficiently long time to have produced detectable antibodies. Several types of antibody detection assays have been developed for early diagnosis of leptospirosis. These include the haemolytic test, indirect haemagglutination assay, indirect immunofluorescence, indirect IgM ELISA, IgM dot-ELISA, immobilised antigen dipstick and lateral flow assays. While these methods are much simpler than MAT, they still need a lag period after infection before antibodies become detectable. One should be careful while interpreting the test results due to varying sensitivity and specificity of the test method. The ELISA tests have been the most readily applicable for the rapid detection and diagnosis of leptospirosis. Several published studies have compared and evaluated a range of commercially available assays. Treatment with effective antibiotics should be initiated as soon as the diagnosis of leptospirosis is suspected and preferably before the fifth day after the onset of illness. The benefit of antibiotics after the fifth day of the disease is controversial. However, most clinicians treat with antibiotics regardless of the date of onset of the illness. These was done in all of these cases and there was no death among the four positive cases.

\section{REFERENCES}

[1] Unnikrisnan D, Pisharody R, Vijaylakshmy N. Prognostic factors in leptospirosis: a study from Kerala, India. Infect Dis in Clin Pract 2005;13(3):1047.

[2] DebMandal M, Mandal S, Pal NK. Serologic evidence of human leptospirosis in and around Kolkata, India: a clinico-epidemiological study. Elsevier Asian Pacific Journal of Tropical Medicine 2011;4(12):1001-6.

[3] Park SK, Lee SH, Rhee YK, et al. Leptospirosis in Chonbuk Province Korea in 1987: a study of 93 patients. Am J Trop Med Hyg 1989;41(3):343-51.

[4] Da Silva JJP, Dalston MO, de Carvalho JEM, et al. Clinicopathological and immunohistochemical features of the severe pulmonary form of leptospirosis. Rev Soc Bras Med Trop 2002;35(4):3959.

[5] Helmerhorst HJ, van Tol EN, Tuinman PR, et al. Severe pulmonary manifestation of leptospirosis. Neth J Med 2012;70(5):215-21.

[6] Riwidikno H, Uji Beda. In: Kesehatan S. edr. Belajar mudah teknik analisis data dalam Penelitian Kesahatan. Jogjakarta: Mitra Cendika Press 2007:4-70.

[7] Vijayachari P, Sugunan AP, Sharma S, et al. Leptospirosis in the Andaman Islands, India. Trans $\mathrm{R}$ Soc Trop Med Hyg 2008;102(2):117-22.

[8] Yang HY, Hsu PY, Pan MJ, et al. Clinical distinction and evaluation of leptospirosis in Taiwan: a case control study. J Nephrol 2005;18(1):45-53.

[9] Mathew T, Satishchandra P, Mahadevan A, et al. Neuroleptospirosis - revisited: experience from tertiary care neurological centre from south India. Indian J Med Res 2006;124(2):155-62.

[10] Chowdry AK. Jaundice in Port Blair, Andaman Islands. Indian Med Gaz 1903;38(11):409-11. 